\title{
The effect of dietary fibre isolates on gastric secretion, acidity and emptying
}

\author{
BY K. TADESSE* \\ Department of Physiology, Guy's Hospital Medical School, London SEI 9RT
}

(Received 29 May 1985 - Accepted 6 January 1986)

1. In six volunteers, the effect of intragastric administration of different water-soluble chemical isolates of
dietary fibre on gastric secretion, acidity and emptying was studied.
2. At $30 \mathrm{~min}$ after administration of the test meals, the stomach contents were completely aspirated and the
volume, $\mathrm{pH}$, phenol red concentration, totai titratable acidity and different electrolytes were measured.
3. Compared with the control meal, the pH and unionized (combined) hydrogen concentrations were significantly
higher $(P<0.05)$ following most of the fibre-containing meals, while the total titratable acid concentration was
not significantly different. None of the fibre-containing meals appreciably altered the volume or type of gastric
secretion but had a low-grade variable effect on gastric emptying.
4. It is concluded that most dietary fibre isolates, although having a definite and notable buffering effect on the
acid in the stomach, have a minimal effect on gastric secretion and a variable and small effect on gastric emptying.

There have been several reports of studies investigating the effects of dietary fibre on different aspects of gastric function (Royal College of Physicians of London, 1980). One of the well-documented observations is the effect of fibre on gastric emptying, but most of the evidence on which it is based is indirect. The few direct studies to date are conflicting and difficult to interpret (McCance et al. 1953; Grimes \& Goddard, 1977; Carryer et al. 1982; Holt et al. 1979). Although the reason for the apparent difference in findings is partly due to differences in methodology, of much more importance may be the heterogeneity of the fibre type used and the unavoidable variation in the levels of the different chemical components. Another aspect of gastric function which has attracted attention recently is the effect of fibre on acid secretion. In vitro studies show that fibre, because of its ion-binding properties, binds different acids (McConnell et al. 1974; Jalan et al. 1977). There is also some suggestion from human studies that dietary fibre may have some acid-buffering effect (Lennard-Jones et al. 1968; Jalan et al. 1979). This is further supported by epidemiological observations and by two clinical trials which show that the frequency of duodenal ulcer recurrence was much reduced while on a diet with a high-fibre content (Malhotra, 1978; Rydning et al. 1982). As in gastric emptying, the evidence for the possible action on gastric acidity is mainly indirect and there is a need for standardization of the fibre source. There is also lack of identification of the chemical(s) responsible for this action from the heterogenous mixture that constitutes the entity recognized as dietary fibre.

It is desirable to investigate the effect of fibre as eaten, but the chemical complexity of the substance makes interpretation of the results very difficult. Moreover, using fibre in its natural form may introduce other nutrient variables which may have an effect on gastric function. Alternatively, studies using defined chemical isolates may obviate these problems and lead to a further understanding of the physiological role of dietary fibre.

The purpose of the present study was to investigate the individual effects of different water-soluble chemical isolates of dietary fibre on gastric acidity, secretion and emptying when administered in physiological amounts and in liquid form.

\footnotetext{
* Present address: Department of Physiology, The Chinese University of Hong Kong, Shatin, N.T., Hong Kong.
} 
Table 1. Composition of the test meals

\begin{tabular}{|c|c|c|c|c|c|c|c|c|}
\hline \multirow[b]{2}{*}{ Test meal } & \multirow{2}{*}{$\begin{array}{l}\text { Glucose } \\
(\mathrm{g} / \mathrm{l})\end{array}$} & \multirow{2}{*}{$\begin{array}{l}\text { Fibre } \\
(\mathrm{g} / \mathrm{l})\end{array}$} & \multirow{2}{*}{$\begin{array}{l}\text { Phenol red } \\
(\mathrm{mg} / \mathrm{l})\end{array}$} & \multirow{2}{*}{$\begin{array}{l}\text { Starting } \\
\text { pH }\end{array}$} & \multirow{2}{*}{$\begin{array}{l}\text { Osmolality* } \\
\text { (mosm/kg) }\end{array}$} & \multicolumn{3}{|c|}{ Electrolytes $(\mathrm{mmol} / \mathrm{l})^{*}$} \\
\hline & & & & & & Chloride & Sodium & Potassium \\
\hline Control & 125 & - & 60 & $7 \cdot 7$ & 640 & $2 \cdot 0$ & $3 \cdot 0$ & $0 \cdot 2$ \\
\hline CM-cellulose ${ }^{\dagger}$ & 125 & 10 & 60 & $7 \cdot 8$ & 670 & $5 \cdot 0$ & $16 \cdot 0$ & $0 \cdot 3$ \\
\hline LM-pectin $\ddagger$ & 125 & 10 & 60 & $4 \cdot 5$ & 660 & $9 \cdot 0$ & $9 \cdot 0$ & 02 \\
\hline HM-pectinf & 125 & 10 & 60 & $4 \cdot 2$ & 680 & $8 \cdot 0$ & $17 \cdot 0$ & $0 \cdot 2$ \\
\hline Raffinose & 125 & 10 & 60 & $7 \cdot 7$ & 670 & $2 \cdot 0$ & $2 \cdot 5$ & $0 \cdot 2$ \\
\hline $\begin{array}{l}\text { CM-cellulose }+ \\
\text { LM-pectin }\end{array}$ & 125 & $5+5$ & 60 & $6 \cdot 1$ & 665 & 6.0 & $12 \cdot 0$ & $0 \cdot 3$ \\
\hline
\end{tabular}

CM, sodium carboxymethyl; LM, low-methoxylated; HM, high-methoxylated.

* Measured after $\mathrm{pH}$ adjustment to $7 \cdot 4$.

$\dagger$ Hercules Incorporation, Oak Brook, Illinois, USA.

$\ddagger$ Citrus Growers Incorporation, Ontario, California, USA.

$\S$ BDH Chemicals Ltd, Poole, Dorset.

\section{MATERIALS AND METHODS}

Six normal volunteers (five male and one female) were trained to swallow stomach tubes by themselves, and a modified procedure of Hunt \& Spurrell (1951) was used to study gastric function. This procedure involved a $12 \mathrm{~h}$ fast followed by swallowing a stomach tube (Levin type, $18 \mathrm{FG}$ ) in the morning and aspiration of the basal secretion. The tube was positioned in the distal part of the stomach using a water recovery test (Hassan \& Hobsley, 1970; Findlay et al. 1972). The stomach was then washed with a total amount of $100 \mathrm{ml}$ water at $37^{\circ}$.

A $400 \mathrm{ml}$ portion of the test meal (Table 1) at $\mathrm{pH} 7.40$ and $37^{\circ}$ was instilled through the tube randomly and on different days. The subject then sat for the following $30 \mathrm{~min}$ with the tube in place, spitting saliva into a beaker. After $30 \mathrm{~min}$ the gastric contents were aspirated completely within $5 \mathrm{~min}$, followed by rinsing of the stomach with a total of $100 \mathrm{ml}$ water. The procedure was approved by the Ethical Committee of Guy's Hospital Medical School (EC81/7/9).

Measurements of the volume, phenol red concentration, $\mathrm{pH}$, total titratable acidity, total bile acids and different electrolytes were made in the meal and aspirate as well as the rinse. Phenol red was measured colorimetrically (Model 250; Corning, New York). The pH was determined using a $\mathrm{pH}$ meter with glass electrode (Titrator TTT1; Radiometer, Copenhagen, Denmark) standardized at $\mathrm{pH} 1 \cdot 68,7 \cdot 38$ and $10 \cdot 01$. Total titratable acid was assessed by automatic titration to $\mathrm{pH} 7 \cdot 40$ using $0.1 \mathrm{M}$-sodium hydroxide. Chloride concentration was measured potentiometrically using a silver-platinum electrode and titrated with $0.2 \mathrm{M}$-silver nitrate (Titrator TTT1; Radiometer). Sodium and potassium were analysed with a flame photometer (Model 400; Corning) and total bile acid content measured using an enzymic method (Fausa \& Skalhegg, 1974).

All samples containing a total bile acid content above $0.1 \mathrm{mmol} / 1$ were discarded. Hydrogen ion concentration (free acid), unionized $\mathrm{H}$ (combined acid) and total titratable acidity (total acid) were calculated by the method of Moore \& Scarlata (1965). Gastric secretion and emptying were calculated using the method of Hunt (1951).

The test meals were also titrated in vitro to determine their titration curves so as to assess their acid-buffering capacity and characteristics.

The results are presented as mean values with their standard errors of difference (SED) between means of control and each test meal. Comparisons were made using Wilcoxon's signed-rank test. 
Table 2. Effect of different water-soluble dietary fibre isolates on gastric acidity $30 \mathrm{~min}$ after intragastric administration of a test meal

(Mean values with their standard errors of difference (SED) between control and dietary treatments for six subjects)

\begin{tabular}{|c|c|c|c|c|c|c|c|c|}
\hline \multirow[b]{2}{*}{ Test meal } & \multicolumn{2}{|c|}{$\mathrm{pH}$} & \multicolumn{2}{|c|}{$\begin{array}{c}\text { Total } \\
\text { titratable } \\
\text { acidity } \\
(\mathrm{mmol} / \mathrm{l})\end{array}$} & \multicolumn{2}{|c|}{$\begin{array}{c}\text { Ionized } \\
\text { (free) } \\
\text { hydrogen } \\
\text { (mmol/1) }\end{array}$} & \multicolumn{2}{|c|}{$\begin{array}{c}\text { Unionized } \\
\text { (combined) } \\
\mathrm{H}(\mathrm{mmol} / \mathrm{l})\end{array}$} \\
\hline & Mean & SED & Mean & SED & Mean & SED & Mean & SED \\
\hline Control & $2 \cdot 18$ & - & $11 \cdot 20$ & - & $9 \cdot 07$ & - & $2 \cdot 13$ & - \\
\hline CM-cellulose & $3 \cdot 98^{*}$ & 0.44 & $13 \cdot 00$ & $5 \cdot 96$ & $0 \cdot 65^{*}$ & 3.59 & $12 \cdot 35^{*}$ & $3 \cdot 43$ \\
\hline LM-pectin & $3.02^{*}$ & $0 \cdot 41$ & $13 \cdot 52$ & $6 \cdot 62$ & $6 \cdot 24$ & $5 \cdot 15$ & $7 \cdot 29^{*}$ & 1.62 \\
\hline CM-cellulose + LM-pectin & $3.55^{*}$ & $0 \cdot 38$ & $12 \cdot 52$ & $5 \cdot 59$ & $1 \cdot 48^{*}$ & $3 \cdot 73$ & $11-04^{*}$ & $2 \cdot 39$ \\
\hline HM-pectin & $3 \cdot 27^{*}$ & 0.44 & $10 \cdot 98$ & $5 \cdot 70$ & $3.03^{*}$ & 3.92 & $7.95^{*}$ & $2 \cdot 21$ \\
\hline Raffinose & $2 \cdot 18$ & $0 \cdot 22$ & $11 \cdot 06$ & $5 \cdot 85$ & $11 \cdot 05$ & $4 \cdot 71$ & $1 \cdot 44$ & $1 \cdot 47$ \\
\hline
\end{tabular}

CM, sodium carboxymethyl; LM, low-methoxylated; HM, high-methoxylated.

$* P<0.05$.

RESULTS

Table 2 shows the means with their SED for the different acid variables measured. The mean $\mathrm{pH}$ of the gastric contents after the control meal was $2 \cdot 18$. Compared with the control meal, all the dietary fibre isolates tested except raffinose significantly $(P<0.05)$ increased the $\mathrm{pH}$ in the gastric contents. The effect was particularly marked after the cellulose meal (3.98 (SED 0.44)) while the addition of raffinose to the control meal made no significant difference $(2 \cdot 18$ (SED 0.22)).

The concentration of the total titratable acid in the gastric contents did not significantly differ following the different test meals, but the unionized (combined) $\mathrm{H}$ concentration was significantly higher after the fibre-containing meals except for raffinose. The converse was generally true for the ionized (free) $\mathrm{H}$, but the value did not reach a significant level for the low-methoxylated (LM)-pectin meal, although values were higher than the control values in five of the six subjects.

Fig. 1 shows a typical in vitro $\mathrm{pH}$ titration characteristic of some of the test meals. The three meals shown have significantly different requirements for $\mathrm{NaOH}$ to bring about a unit change in their $\mathrm{pH}$, particularly at low $\mathrm{pH}(\mathrm{pH} 2-5)$. Compared with the control meal the cellulose meal is the most resistant to $\mathrm{pH}$ changes (i.e. most active buffer) while pectin is intermediate. The raffinose-containing meal was not different from the control meal.

Table 3 shows the mean volumes of the test meals and gastric secretion remaining in the stomach after $30 \mathrm{~min}$. Compared with the control meal, the sodium-carboxymethyl (CM)-cellulose- and the raffinose-containing meals significantly $(P<0.05)$ decreased gastric emptying. The LM-pectin meal increased gastric emptying in five of the six subjects tested while the high-methoxylated (HM)-pectin decreased gastric emptying in the same number but different individual subjects. Combining LM-pectin and CM-cellulose in equal amounts abolished the effect and gave values which were very similar to that of the control meal (184.7 (SED 17.5) $\mathrm{ml}$ ). There was no significant difference in the mean volume of gastric secretion remaining in the stomach $30 \mathrm{~min}$ after the different meals, although values for the pectin meals tended to be low. There also appeared to be no difference in the hypothetical parietal and non-parietal components. 


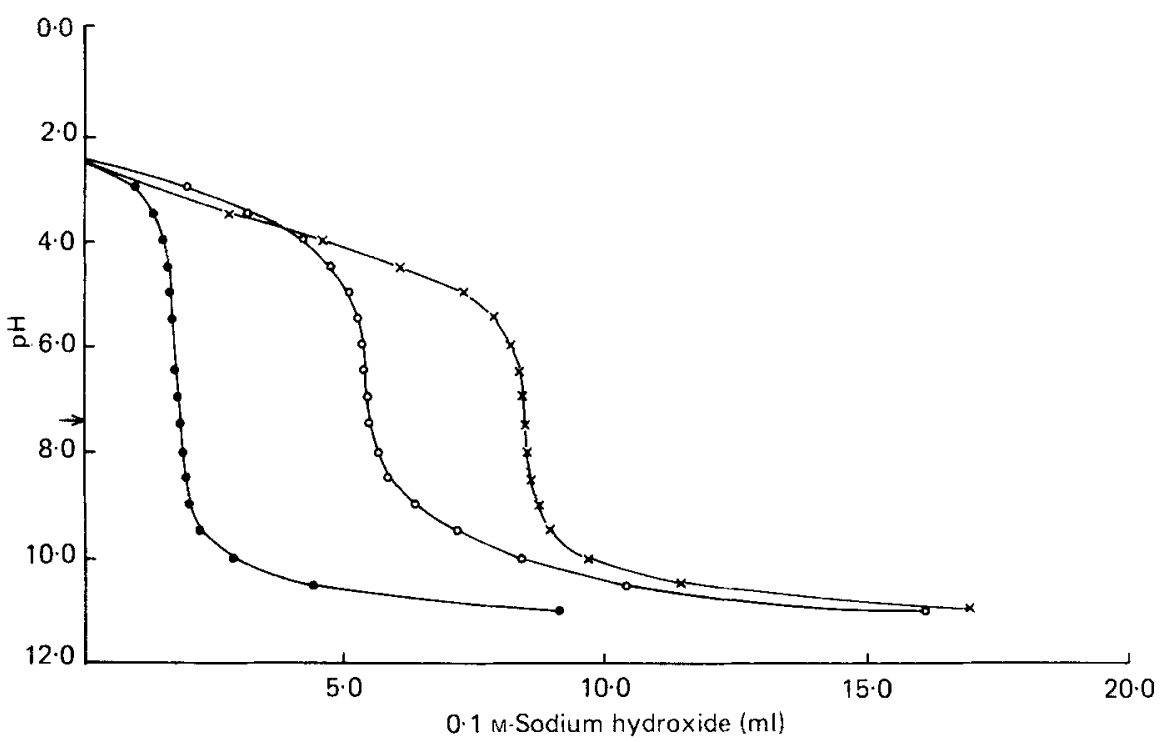

Fig. 1. In vitro $\mathrm{pH}$ titration of some of the test meals used in the experiment. Control meal (O), low-methoxylated-pectin meal $(O)$, sodium carboxymethyl-cellulose meal $(x)$. For details of test meals, see Table 1 .

Table 3. Effect of different water-soluble dietary fibre isolates on gastric secretion and emptying

(Mean values with their standard errors of difference (SED) between control and dietary treatments for six subjects)

\begin{tabular}{|c|c|c|c|c|c|c|c|c|}
\hline \multirow[b]{4}{*}{ Test meal } & \multicolumn{8}{|c|}{ Volume remaining in the stomach at $30 \mathrm{~min}(\mathrm{ml})$} \\
\hline & & & & & Secre & & & \\
\hline & \multicolumn{2}{|c|}{ Meal } & \multicolumn{2}{|c|}{ Parietal } & \multicolumn{2}{|c|}{ Non-parietal } & \multicolumn{2}{|c|}{ Total } \\
\hline & Mean & SED & Mean & SED & Mean & SED & Mean & SED \\
\hline Control & $182 \cdot 7$ & - & $20 \cdot 7$ & - & $14 \cdot 3$ & - & $35 \cdot 0$ & - \\
\hline CM-cellulose & $229 \cdot 5^{*}$ & $21 \cdot 2$ & $29 \cdot 4$ & $9 \cdot 4$ & $17 \cdot 9$ & $4 \cdot 6$ & $47 \cdot 3$ & $10 \cdot 8$ \\
\hline LM-pectin & $134 \cdot 8$ & $19 \cdot 8$ & $16 \cdot 6$ & $9 \cdot 5$ & $6 \cdot 6$ & $4 \cdot 1$ & $23 \cdot 3$ & $10 \cdot 2$ \\
\hline CM-cellulose + LM-pectin & $184 \cdot 7$ & $17 \cdot 5$ & $22 \cdot 2$ & $8 \cdot 6$ & $10 \cdot 8$ & $4 \cdot 2$ & $33 \cdot 0$ & $10 \cdot 4$ \\
\hline HM-pectin & $224 \cdot 0$ & $23 \cdot 3$ & $20 \cdot 1$ & $8 \cdot 7$ & $5 \cdot 9$ & $3 \cdot 7$ & $26 \cdot 0$ & $9 \cdot 5$ \\
\hline Raffinose & $226 \cdot 5^{*}$ & $20 \cdot 4$ & $23 \cdot 2$ & $8 \cdot 8$ & $12 \cdot 3$ & $5 \cdot 4$ & $35 \cdot 4$ & $11 \cdot 7$ \\
\hline
\end{tabular}

CM, sodium carboxymethyl; LM, low-methoxylated; HM, high-methoxylated.

* $P<0.05$.

\section{DISCUSSION}

Several factors may influence gastric secretions and emptying after a meal. Amongst the important ones are the volume, type of nutrient, energy density, consistency, viscosity, $\mathrm{pH}$ and temperature. Most of these variables were not significantly different in the different test meals used in the present study and as such could not be expected to contribute markedly to the observed results. The only possible variables of importance were the presence or absence of fibre, the chemical type of the fibre and possibly the viscosity of the meal. 
The present finding that the addition of CM-cellulose or HM-pectin or raffinose to the control meal delayed gastric emptying is in agreement with currently accepted views (Royal College of Physicians of London, 1980). Holt et al. (1979), using radiolabelled standard test meals to which were added pectin $(10 \mathrm{~g})$ and guar gum $(16 \mathrm{~g})$, found that the amount of meal emptied in the first 30 min was about $34 \%$ with the fibre-containing meal compared with about $54 \%$ with the control meal. In the present study, although the effect on gastric emptying was similar, the magnitude of the effect was less. This presumably was due to the smaller amount of fibre administered, but the effect of viscosity cannot be ruled out. Leeds et al. (1981), using HM-pectin $(10.6 \mathrm{~g})$, found that $50 \%$ of the test meal was emptied in about 30 min while the same amount of their control meal took only about $12 \mathrm{~min}$. The results for the HM-pectin in the present study are in agreement with their findings but again the larger effect in their study may be due to the higher amount of HM-pectin used.

In the light of these findings the effect of the LM-pectin meal observed in the present study is very interesting and may partly explain the conflicting reports of McCance et al. (1953) and Grimes \& Goddard (1977). Unlike the other fibre isolates, the addition of LM-pectin to the control meal increased gastric emptying. This effect of LM-pectin does not appear to be spurious since combining it with CM-cellulose and administering it in the same manner abolished the difference from the control meal. Presumably this is due to opposing actions by the two fibre isolates and implies that the effect of dietary fibre on gastric emptying may vary depending on the chemical characteristics of the fibre source. Since the dietary fibre one gets from different plant sources, and in a mixed diet, varies both in composition and the relative proportion of each component (Cummings, 1976), the sum effect on gastric emptying would be expected to be variable and difficult to predict.

One explanation forwarded for the effect of fibre on gastric emptying has been the increased viscosity of meals containing fibre (Jenkins et al. 1978; Holt et al. 1979). Hunt (1954), using citrus pectin in his classic studies on gastric function, observed that viscosity of a test meal had no effect on the emptying and secretory pattern of the stomach. In contrast, Ehrlein \& Pröve (1982), studying the effect of viscosity of glucose test meals in five dogs, found that the rate of gastric emptying was dependent on viscosity. They attributed their different findings to the very-high-viscosity test meals they were using. However, some recent reports have also raised doubts about the role of viscosity in gastric emptying (Wolever et al. 1978; O'Connor et al. 1981). Although in the present study viscosity was not measured, the following three observations make it an unlikely explanation for the observed effects. First, the test meals containing pectin were expected to be and appeared more viscous than the other meals and yet had opposite effects; i.e. the LM-pectin increased gastric emptying and the HM-pectin decreased it. Second, the raffinose meal, the least viscous of the fibre meals and virtually similar to the control meal, delayed gastric emptying. Third, adding to the control meal CM-cellulose and LM-pectin together, despite making the meal relatively more viscous, did not have a significant effect on gastric emptying.

Another variable which may affect the result of an experiment such as this is streaming, i.e. the separation of the meal into different phases emptying at different rates (Malagelada, 1977). This probably did not occur since centrifugation of the meals at $2500 \mathrm{rev} . / \mathrm{min}$ with the $\mathrm{pH}$ adjusted in the range of 1.5-6.0 did not produce separation. Moreover, there was no apparent increase in the concentration of the fibre isolate administered in any of the aspirated samples.

The $\mathrm{pH}$ of the stomach contents was markedly different following the different test meals (Table 2). This could be due to (1) variation in the amount of gastric secretion, (2) variation in intragastric content, (3) an acid-buffering effect following the different meals. The first two variables do not seem to be major contributors to the observed difference since there 
was no statistically significant quantitative or qualitative difference in gastric secretion after the various meals (Table 3). There was also no relation between $\mathrm{pH}$ and the amount of test meal remaining in the stomach at $30 \mathrm{~min}$. Moreover, the concentration of the total acid in the gastric contents aspirated remained similar despite the low-grade variation in gastric emptying following the different test meals (Table 2). It would appear that the amount of the secretion emptied was proportional to the test meals being emptied, indicating a good mixing. In this situation the third variable (i.e. buffering) was the most likely cause for the difference and since $\mathrm{pH}$ was invariably higher after the fibre-containing meals, except raffinose, it would be reasonable to assume that the fibres were acting as buffers to the acid.

This observation is also supported by two similar studies. Jalan et al. (1979), comparing the effect of administration of two meals (rice-based and wheat-based) to normal subjects and patients with duodenal ulcers, found that acid secretion rate after the two meals was not different but the buffering capacity of the wheat-based meal was higher in both groups. Lennard-Jones et al. (1968), in their study of the effect of different mixed diets on the acidity of the gastric contents in patients with duodenal ulcers, showed that the mean gastric $\mathrm{pH}$ was higher after the high-protein and high-dietary-fibre meals. In both these reports, although some of the major nutrients in the test meals (e.g. protein) were different, the most marked difference and the likely factor responsible for the buffering action appears to have been their dietary fibre content.

In the previously-quoted studies it could be argued that saliva may have contributed to the buffering of the acid in the stomach, particularly since a high-fibre diet is thought to increase salivary secretion due to the increased mastication required (Malhotra, 1978). The present study has attempted to avoid both the effects of other nutrients and mastication by instilling pure chemical isolates of fibre directly into the stomach.

The effectiveness of the buffering action was found to be dependent on the chemical type of the fibre. CM-cellulose was the most active buffer and raffinose the least. This observation was further supported by the in vitro studies, which clearly showed buffering action by the major fibre isolates, particularly at $\mathrm{pH}$ ranges usually encountered in the stomach. In addition, the findings on the distribution of the acid in the stomach content (i.e. free and combined acid) after the different meals unequivocally demonstrate binding of $\mathrm{H}^{+}$by the major chemical isolates of dietary fibre in vivo (Table 2).

In conclusion, the results of the present study suggest that dietary fibre isolates, although not having a discernible effect on gastric secretion, have a marked buffering effect on the acid in the stomach. Their effect on gastric emptying is variable and small in magnitude and is unlikely to be due to variation in viscosity. The magnitude of the buffering action and the effect on the gastric emptying appears to be dependent on and specific to the chemical characteristics of the fibre employed. The seemingly contradictory results on gastric emptying found in the literature may be explained by the difference in the chemical composition of the whole-fibre source used.

\section{REFERENCES}

Carryer, P. W., Brown, M. L., Malagelada, J.-R., Carlson, G. L. \& McCall, J. T. (1982). Gastroenterology 82, $1389-1394$.

Cummings, J. H. (1976). In Fiber in Human Nutrition, pp. 1-30 [G. A. Spiller and R. J. Amen, editors]. New York: Plenum Press.

Ehrlein, H.-J. \& Pr̈ove, J. (1982). Quarterly Journal of Experimental Physiology 67, 419-425.

Fausa, D. \& Skalhegg, B. A. (1974). Scandinavian Journal of Gastroenterology 9, 249-254.

Findlay, J. M., Prescott, R. J. \& Sircus, W. (1972). British Medical Journal iv, 458-461.

Grimes, D. S. \& Goddard, J. (1977). Gut 18, 725-729.

Hassan, M. A. \& Hobsley, M. (1970). British Medical Journal i, 458-460.

Holt, S., Heading, R. C., Carter, D. C., Prescott, L. F. \& Tothill, P. (1979). Lancet i, 636-639. 
Hunt, J. N. (1951). Journal of Physiology 113, 169-184.

Hunt, J. N. (1954). Lancet i, 17-18.

Hunt, J. N. \& Spurrell, W. R. (1951). Journal of Physiology 113, 157-168.

Jalan, K. N., Mahalanabis, D., Maitra, T. K. \& Agarwal, S. K. (1979). Gut 20, 389-393.

Jalan, K. N., Maitra, T. K., Mahalanabis, D., Agarwal, S. K., Chakraborty, M. L., Chattoraj, D. K. \& Moulik, S. P. (1977). Journal of Food Science 42, 1675-1676.

Jenkins, D. J. A., Wolever, T. M. S., Leeds, A. R., Gassull, M. A., Haisman, P., Dilawari, J., Goff, D. V., Metz, G. L. \& Alberti, K. G. M. M. (1978). British Medical Journal i, 1392-1394.

Leeds, A. R., Ralphs, D. N. L., Ebied, F., Metz, G. \& Dilawari, J. B. (1981). Lancet i, 1075-1078.

Lennard-Jones, J. E., Fletcher, J. \& Shaw, D. G. (1968). Gut 9, 177-182.

McCance, R. A., Prior, R. M. \& Widdowson, E. M. (1953). British Journal of Nutrition 98, 98-104.

McConnell, A. A., Eastwood, M. A. \& Mitchell, W. D. (1974). Journal of the Science of Food and Agriculture 25, 1457-1464.

Malagelada, J.-R. (1977). Gastroenterology 72, 1264-1267.

Malhotra, S. L. (1978). Postgraduate Medical Journal 54, 6-9.

Moore, E. W. \& Scarlata, R. W. (1965). Gastroenterology 49, 178-188.

O'Connor, N., Tredyer, J. \& Morgan, L. (1981). Diabetologia 20, 612-615.

Royal College of Physicians of London (1980). Report on Medical Aspects of Dietary Fibre. Kent: Pitman Medical. Rydning, A., Berstad, A., Aadland, E. \& Ødegaard, B. (1982). Lancet ii, 736-738.

Wolever, T. M. S., Taylor, R. \& Goff, D. V. (1978). Lancet ii, 1381. 